OPEN ACCESS

Edited by:

Alessio Fini,

University of Florence, Italy

Reviewed by:

Anca Macovei,

University of Pavia, Italy

Myrtill Simkó,

Austrian Institute of Technology,

Austria

*Correspondence:

Marcin Łukaszewicz

marcin.lukaszewicz@uwr.edu.pl

Specialty section:

This article was submitted to

Functional Plant Ecology,

a section of the journal

Frontiers in Plant Science

Received: 23 September 2016 Accepted: 27 January 2017

Published: 07 March 2017

Citation:

Sztafrowski D,

Aksamit-Stachurska A, Kostyn K,

Mackiewicz $P$ and $Ł u k a s z e w i c z ~ M$

(2017) Electromagnetic Field Seems

to Not Influence Transcription via

CTCT Motif in Three Plant Promoters.

Front. Plant Sci. 8:178.

doi: $10.3389 /$ fpls.2017.00178

\section{Electromagnetic Field Seems to Not Influence Transcription via CTCT Motif in Three Plant Promoters}

\author{
Dariusz Sztafrowski ${ }^{1}$, Anna Aksamit-Stachurska ${ }^{2}, K^{2}$ Kamil Kostyn ${ }^{2}$, Paweł Mackiewicz ${ }^{2}$ \\ and Marcin Łukaszewicz²*
}

${ }^{1}$ Faculty of Electrical Engineering, Wrocław University of Science and Technology, Wrocław, Poland, ${ }^{2}$ Faculty of Biotechnology, University of Wrocław, Wrocław, Poland

It was proposed that magnetic fields (MFs) can influence gene transcription via CTCT motif located in human HSP70 promoter. To check the universality of this mechanism, we estimated the potential role of this motif on plant gene transcription in response to MFs using both bioinformatics and experimental studies. We searched potential promoter sequences (1000 bp upstream) in the potato Solanum tuberosum and thale cress Arabidopsis thaliana genomes for the CTCT sequence. The motif was found, on average, 3.6 and 4.3 times per promoter (148,487 and 134,361 motifs in total) in these two species, respectively; however, the CTCT sequences were not randomly distributed in the promoter regions but were preferentially located near the transcription initiation site and were closely packed. The closer these CTCT sequences to the transcription initiation site, the smaller distance between them in both plants. One can assume that genes with many CTCT motifs in their promoter regions can be potentially regulated by MFs. To check this assumption, we tested the influence of MFs on gene expression in a transgenic potato with three promoters (16R, 20R, and 5UGT) containing from 3 to 12 CTCT sequences and starting expression of $\beta$-glucuronidase as a reported gene. The potatoes were exposed to a $50 \mathrm{~Hz} 60-70 \mathrm{~A} / \mathrm{m} \mathrm{MF}$ for $30 \mathrm{~min}$ and the reporter gene activity was measured for up to $24 \mathrm{~h}$. Although other factors induced the reporter gene activity, the MF did not. It implies the CTCT motif does not mediate in response to MF in the tested plant promoters.

\section{Keywords: Arabidopsis thaliana, electromagnetic field responsive element, CTCT, Solanum tuberosum, $50 \mathrm{~Hz}$} magnetic field

\section{INTRODUCTION}

During the life cycle organisms are continually exposed to various external stimuli, which requires adequate responses to maintain homeostasis; this process is often called a stress response. The stress factors cause changes in gene expression resulting in adaptive responses at the proteome (synthesis of relevant proteins) or metabolome levels (production of appropriate metabolites, e.g., antioxidants) (Łukaszewicz and Szopa, 2005).

One of such factors could be extremely low-frequency magnetic fields (ELF-MFs), which influence living organisms are supported by the increasing number of evidences. However, the failure to produce repeatable effects (Heredia-Rojas et al., 2010; Buchachenko, 2016) has made this study difficult and the subject questionable (Blank and Goodman, 2011a; Foster, 2011). Despite 
many studies, the mechanisms of MF influence are still at the stage of hypotheses rather than well-documented scientific models (Zaporozhan and Ponomarenko, 2010; D'Angelo et al., 2015). Among the various proposed mechanisms, the influence of ELF-MFs on DNA via gene expression is a challenge to test. The interaction could be direct, e.g., DNA can act as fractal antennae (Blank and Goodman, 2011b), or indirect, e.g., free radicals, the circadian clock, or calcium-related pathways can participate in the response (Sztafrowski et al., 2011; Manzella et al., 2015). The influence of ELF-MFs on gene transcription could be mediated by specific sequences, which were found in promoter regions in animals. Indeed, a hypothesis has been proposed that CTCT sequences might act as electromagnetic field response elements (EMREs) in the human HSP70 promoter (Lin et al., 2001). However, it was criticized by other researches (e.g., Alfieri et al., 2006).

Several regulatory mechanisms are similar in animals and plants, especially general stress responses to factors like heat shock or heavy metals (Aksamit et al., 2005). Some data indicate that plants, like animals, perceive and respond to varying MFs by altering their gene expression and phenotypes (Maffei, 2014). However, the influence of MFs on CTCT was studied only in animals and never in plants. It would be interesting to check if these motifs are universal and also mediate responses to ELFMFs in plants. Therefore, to further examine the hypothesis about CTCT acting as EMRE motifs, we selected a plant model. In particular, we tested if the CTCT motif can regulate gene transcription in response to MF stress in plants. For this purpose, putative promoter regions of all annotated proteincoding nuclear genes from Solanum tuberosum and Arabidopsis thaliana were analyzed in silico. Subsequently, this hypothesis was experimentally evaluated using three promoters that contained CTCT motifs. We selected 16R, 20R and 5UGT promoters, which are involved in flavonoid biosynthesis regulation and responses to free radical stress. The free radicals influence the regulation of genes related to the flavonoid biosynthetic pathway, such as glucose transferase (Lorenc-Kukuła et al., 2004; Korobczak et al., 2005), or regulatory genes encoding 14-3-3 proteins (Szopa et al., 2003a,b; Łukaszewicz et al., 2004). To study the MFs influence, we measured $\beta$-glucuronidase (GUS) activity driven by the promoters in a transgenic potato with and without exposure to a $60-70 \mathrm{~A} / \mathrm{m} \mathrm{MF}$.

\section{MATERIALS AND METHODS}

\section{Plant Material and Bacterial Strains}

To transform the potato plants (S. tuberosum L. cv. Desiree) obtained from Saatzucht Fritz Lange KG (Bad Schwartau, Germany), three promoters were used: 20R (EMBL/GenBank database acc. no. AY518222), 5UGT (EMBL/GenBank database acc. no. AY033489), and 16R (EMBL/GenBank database acc. no. AY070220). Each promoter regulated transcription of the reporter gene uidA (coding for $\beta$-glucuronidase). For plants transformation binary vector pBI101 (Clontech, Mountain View, CA, USA) and Agrobacterium tumefaciens strain C58C1 were used. Plants were grown in tissue culture under 16-h light
(23 $\mathrm{mmol} / \mathrm{s} / \mathrm{m}^{2}$ ) - 8-h dark regime in MS medium (Murashige and Skoog, 1962) containing $0.8 \%$ sucrose. Plants in the greenhouse were cultivated in soil under 16 -h light (in $22^{\circ} \mathrm{C}$ temperature) - 8-h dark (in $15^{\circ} \mathrm{C}$ ) regime. Plants were grown in individual pots and watered daily.

\section{Fluorometric GUS Assay}

Transcriptional activity of the tested promoters in transgenic plants was measured by GUS reporter gene activity (Łukaszewicz et al., 1998). Briefly, samples were extracted with $50 \mathrm{mM}$ Tris buffer ( $\mathrm{pH}$ 8.0) containing $10 \mathrm{mM} \beta$-mercaptoethanol and $10 \mathrm{mM}$ EDTA, and centrifuged for $10 \mathrm{~min}$ at 13 $000 \mathrm{rpm}$. Aliquots of the supernatant were used for an enzyme assay, with 4-methylumbelliferyl $\beta$-D-glucuronide as a substrate (Jefferson et al., 1987), and for protein determination with the Bradford reagent (Bradford, 1976). The reaction product, 4-methylumbelliferone, was measured fluorometrically (SFM 25 Fluorescence Spectrophotometer, Kontron Instrument, Hamburg, Germany).

Bioinformatic analyses of tested promoters 16R, 20R and 5UGT identified several regulatory motifs, which could be recognized by various transcription regulation factors (Szopa et al., 2003b; Lorenc-Kukuła et al., 2004; Aksamit et al., 2005). Based on these results, several putative regulatory factors were experimentally tested for each promoter. In this study, we used the following factors inducing the highest and the fastest promoter expression as positive controls: IAA for 16R promoter (Szopa et al., 2003b), $\mathrm{ZnSO}_{4}$ for 20R promoter (Aksamit et al., 2005) and ABA for 5UGT promoter (Lorenc-Kukuła et al., 2004). GUS activity was measured in leaves (about 8-12 plastochrons old) incubated on the MS medium supplemented with 2.5\% sucrose and $100 \mu \mathrm{M}$ of the inducing factors.

\section{Western Blot Analysis}

An assessment of the GT protein level was conducted by means of western blot analysis using the rabbit anti-GT IgG and Solanum sogarandinum plants. Briefly, the solubilized protein was run on $12 \%$ SDS-polyacrylamide gels and blotted electrophoretically onto nitrocellulose membranes (Schleicher and Schuell, Dassel, Germany). After the transfer, the membrane was sequentially incubated with a blocking buffer (5\% dry milk) and then with antibodies directed against the GT protein (1:500 dilution). Alkaline phosphatase-conjugated goat anti-rabbit IgG served as the second antibody and was used at the dilution of $1: 1500$.

\section{Polymerase Chain Reaction (PCR)}

Pooled samples from at least three samples were used for the total RNA extraction. cDNA was synthesized from $5 \mu \mathrm{g}$ of the total RNA using High Capacity cDNA reverse transcription kit (Applied Biosystems, Poland). cDNA was added to $5 \mu$ l of SYBR Green PCR mix (A\&A Biotechnology, Gdynia, Poland) and $0.5 \mu \mathrm{l}$ of each primer $(0.5 \mu \mathrm{m})$ in triplicate. Polymerase chain reaction (PCR) was carried out with the use of specific primers for glycosyltransferase gene (forward, GTCCTCTTGGTGACATTTCCCACAC and reverse, TGAGGAAATGCCACCACAGGTACAC). Amplification and 
detection were performed using LightCycler 2.0 instrument and lightcycler software version 4.0 (Roche, Warszawa, Poland).

\section{Exposure System}

Plant material was exposed to $50 \mathrm{~Hz} 76-88 \mu \mathrm{T}(60-70 \mathrm{~A} / \mathrm{m}) \mathrm{MF}$ for $30 \mathrm{~min}$ in the air-conditioned room with the temperature of $19^{\circ} \mathrm{C}$. Taking into account the air flow and the layout of exposition with the minimum distance from the plant of several centimeters there was no significant effect of temperature on the experimental results with the applied MF.

The EMF exposure system was composed of two Helmholtz coils with the inside diameter of $400 \mathrm{~mm}$, external diameter of $462 \mathrm{~mm}$, and $40-\mathrm{mm}$ width with $216 \mathrm{~mm}$ spacing. Each of the Helmholtz coils was made of copper wire (2.15 $\mathrm{mm}$ in diameter) coiled for 223 winding turns. Both coils were positioned vertically to ensure that the magnetic flux was generated in the horizontal plane. The output of the autotransformer (ZWE Eltra, Bydgoszcz, Poland) connected to the electric energy supply was an electric source for a sinusoidal $50-\mathrm{Hz}$ alternating current (sinusoidal $50-\mathrm{Hz} \mathrm{MF}$ ) in the experiment. The difference of the potential applied to the coils could be regulated. The amplitude of the current intensity was controlled by the ammeter (Multimeter Fluke 8846A; Fluke, Cleveland, OH, USA). MF strength in the center of the Helmholtz coils can be calculated from the formula derived from Biot-Savart's law:

$$
H_{\text {calculated }}=0,7156 \cdot \frac{N * I}{r}=0,7156 \cdot \frac{223 * I}{0,2155}=740 \cdot I
$$

where: I - value of current

$$
\begin{aligned}
& r-\text { radius of coils } \\
& N-\text { number of winding turns. }
\end{aligned}
$$

Higher harmonic waves in the current were monitored during the experiments (Power Quality analyzer Fluke 43, Fluke, Cleveland, OH, USA) and did not exceed 2\%. Magnetic induction was measured with EPRI - Emdex II meter (Patterson, CA, USA) and with Holaday HI-3627 meter (Eden Prairie, MN, USA) for traceability. MF strength was kept in our experiments within the range of $60-70 \mathrm{~A} / \mathrm{m}$.

Exposure was carried out on potato leaves with $25 \mathrm{~mm}$ long and $15 \mathrm{~mm}$ width. Orientation of leaf's stem was parallel to the force lines of MF generated in the exposure system (Supplementary Figure S1). During the exposure, the leaves were put on Petri dish $(35 \mathrm{~mm} \times 10 \mathrm{~mm})$ positioned in the geometrical center of Helmholtz coils. Additionally, for transgenic plants with $16 \mathrm{R}$ promoter, the whole plants in jars were subjected to exposition.

In the case of frequency $50 \mathrm{~Hz}$, the relevant wave length is about $6000 \mathrm{~km}$, therefore the field produced in the exposure system can be considered quasi stationary, i.e., slowly variable in time. It has been proposed that the field produced by alternating $50 \mathrm{~Hz}$ current can be described by Biot-Savart formula though it is relevant for direct current (DC). Then, the replacement of alternated current with its root mean square

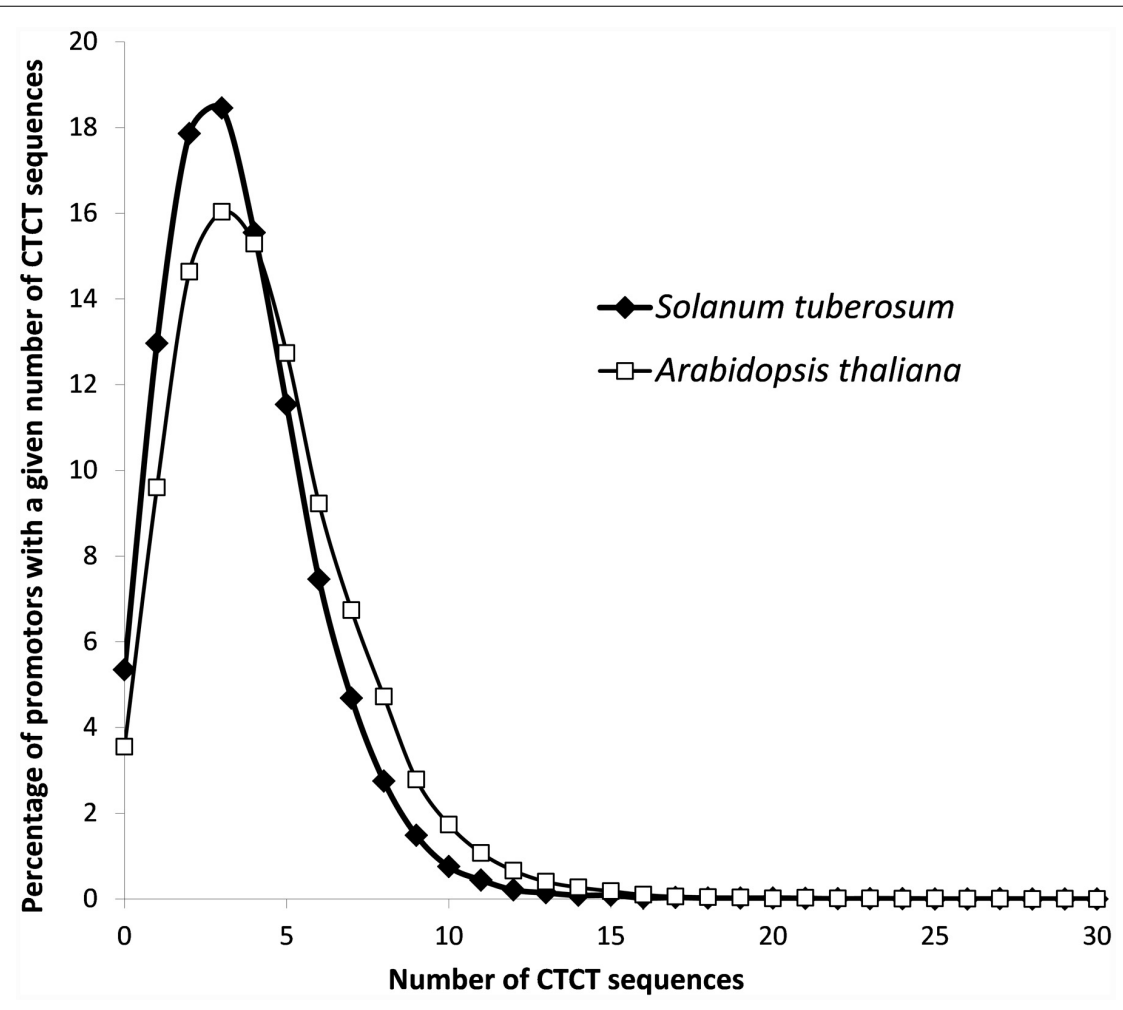

FIGURE 1 | Distribution of СTCT sequences in the set of potential S. tuberosum and Arabidopsis thaliana promoters (1000 nucleotides upstream of the transcription start site). 
(RMS) value allows for determination of the equivalent strength of MF.

\section{Statistical Analyses of Experimental Results}

$t$-test and confidence intervals (CIs) were calculated using Excel (Microsoft, Warszawa, Poland) to assess statistical significance of the obtained results. $p$-values less than 0.05 were considered statistically significant.

\section{Searching and Analysis of Potential EMREs in Plant Promoter Regions}

Potential defined EMREs, i.e., CTCT sequences (Lin et al., 2001), were searched in 41,036 S. tuberosum and 31,036 A. thaliana potential promoter sequences, which were defined as regions of 1000 nucleotides upstream of the transcription initiation site of protein-coding nuclear genes; we excluded sequences with unidentified nucleotides in this study. The scanned promoter sequences and gene annotations were obtained from $S$. tuberosum Group Phureja DM1-3 516R44 (CIP801092) genome annotation v3.4 (Xu et al., 2011), deposited in Phytozome v10.2 (Goodstein et al., 2012), and the Arabidopsis Information Resource (TAIR) database, release 9 (Lamesch et al., 2012). For each promoter region, the observed number of EMRE sequences was compared with its expected number, which was calculated according to the nucleotide composition of the given promoter sequence. The statistical significance of this comparison was assessed in the test of proportion with the Benjamini-Hochberg multiple comparisons procedure for controlling false discovery rate (Benjamini and Hochberg, 1995) as implemented in R package 3.1.1 ( $\mathrm{R}$ Development Core Team, 2014). In the putative EMRE search and analysis, in-house written Perl scripts were used.

\section{RESULTS}

In Poland, according to the Regulation of the Minister of Environment of 30 October 2003 (Dz.U. 2003, Nr 192, poz. 1883), $60 \mathrm{~A} / \mathrm{m}$ is the upper limit intensity for unlimited exposure of humans to $50-\mathrm{Hz}$ MFs. The nCTCTn motif may be responsible for the regulation of gene expression in response to $50-\mathrm{Hz}$ MFs in animal cells (Lin et al., 2001). Therefore, we decided to investigate the potential influence of MFs on plant gene expression involving the EMRE motif.

\section{Frequency and Distribution of Potential EMREs in Plant Promoter Regions}

To analyze the frequency and distribution of the potential EMRE motif within gene promoters in plants, we included two plant representatives, $S$. tuberosum, the subject of the

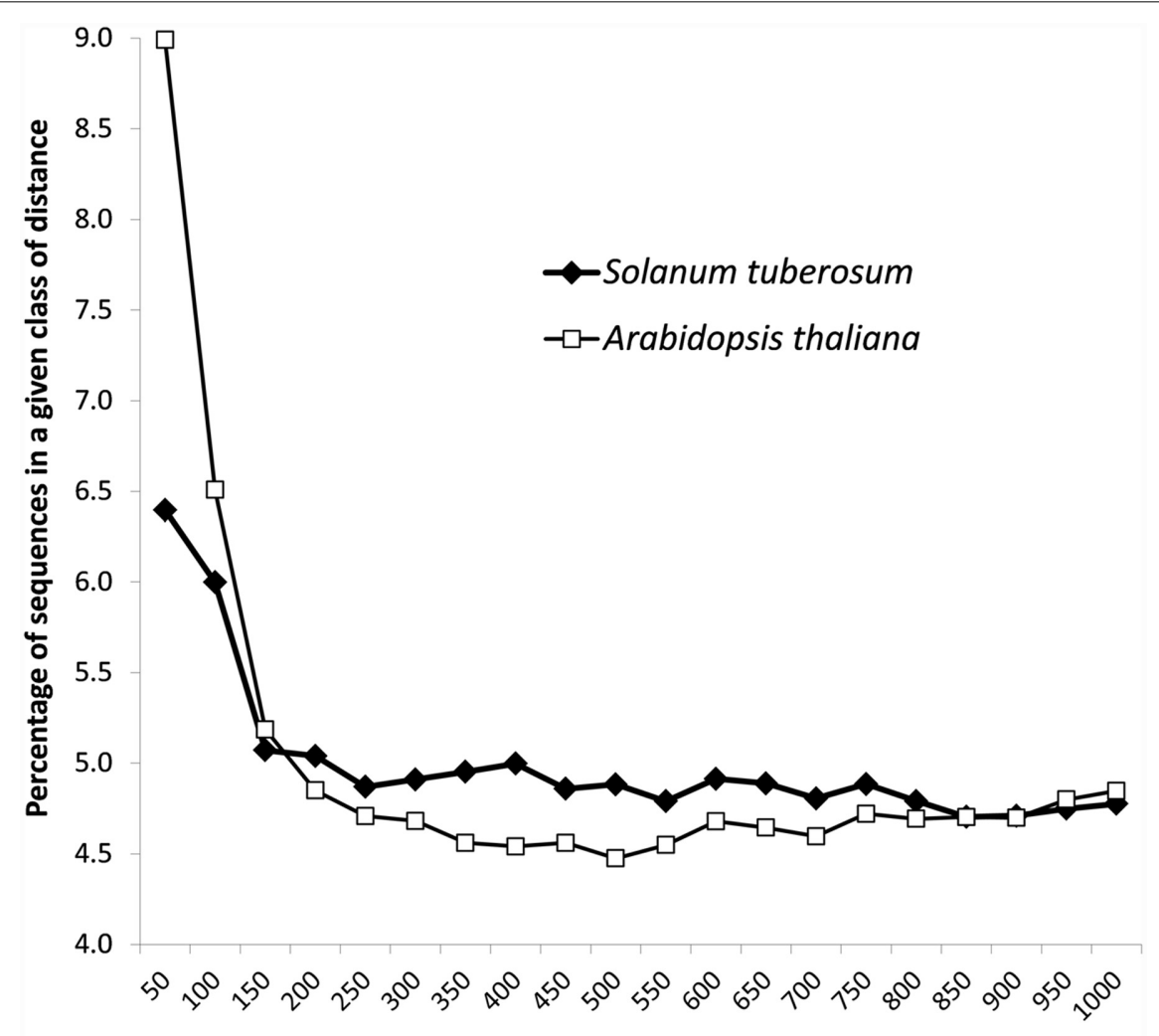

Distance of CTCT sequences from transcription initiation site

FIGURE 2 | Distribution of the distance of СTCT sequences from the transcription start site in S. tuberosum and $A$. thaliana. 


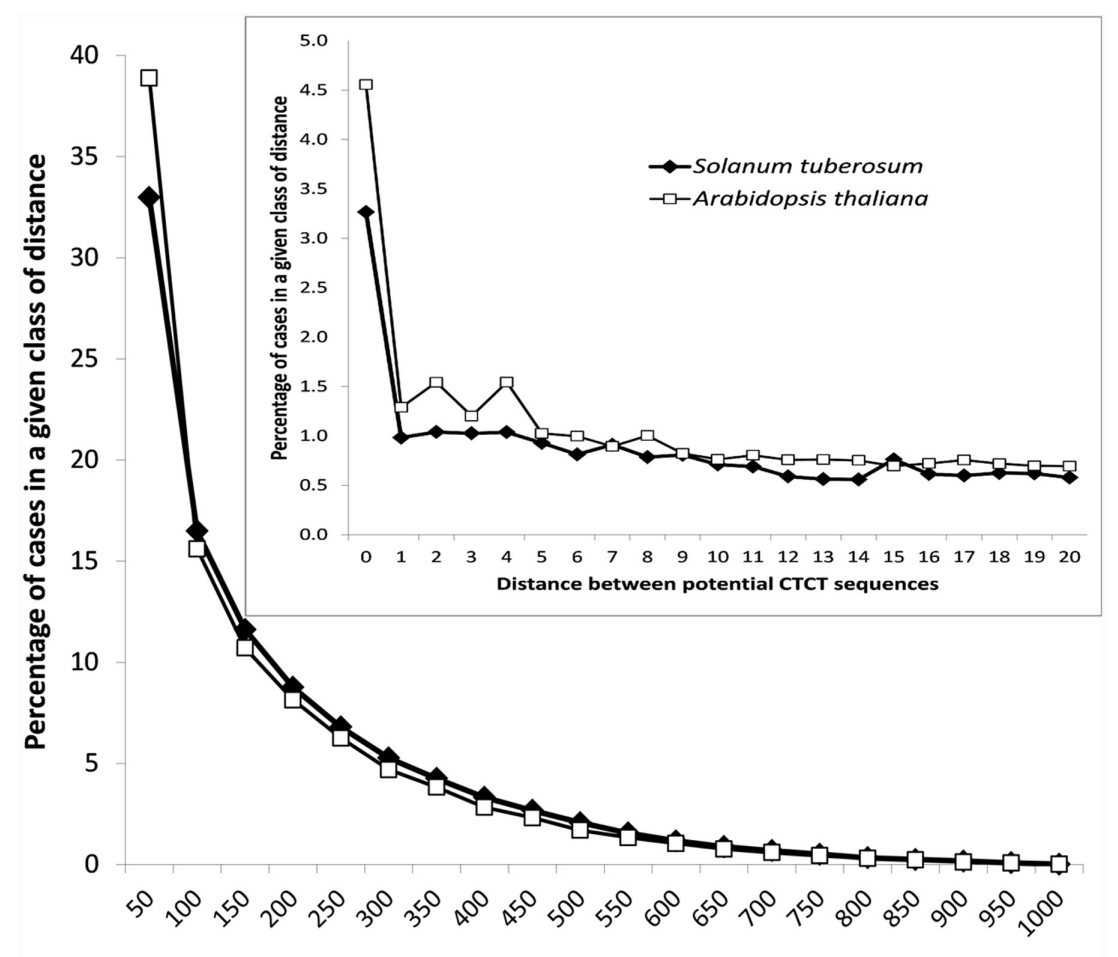

Distance between potential CTCTnsequences

FIGURE 3 | Distribution of the distances between CTCT sequences found in promoter regions of S. tuberosum and $A$. thaliana. The inset shows the distribution in the narrower range from 0 to 20 nucleotides.

experimental studies in this paper, and a popular model plant organism, A. thaliana. The genome of $S$. tuberosum has the total length of $\sim 800 \mathrm{Mb}$ that is arranged into 12 chromosomes (Xu et al., 2011), whereas A. thaliana has the $\sim 135 \mathrm{Mb}$ genome that is organized into five chromosomes (Lamesch et al., 2012). We searched potential 1000 bp-promoter sequences from these two genomes. The analysis identified 148,487 in S. tuberosum and 134,361 in A. thaliana putative EMRE motifs, which gives respective averages of 3.6 and 4.3 such sequences per promoter. In both plants, promoters that contained three CTCT sequences were most abundant (Figure 1). They constituted more than 18\% (7573) in S. tuberosum and $16 \%$ (4977) in A. thaliana of cases. More than $15 \%$ of the promoters (i.e., 6380 in S. tuberosum and 4745 A. thaliana cases) included four potential EMRE sequences, whereas 10 or more motifs were present in 783 S. tuberosum and 1449 and $A$. thaliana promoter regions (Figure 1). The motifs were absent from only 2195 and 1103 promoter regions, respectively.

Detailed analyses revealed that CTCT sequences were not randomly distributed in the promoter regions, but rather located close to the transcription initiation site (Figure 2). Almost 6.5\% and $9 \%$ of these sequences $(9,500$ from $S$. tuberosum and 12,080 A. thaliana) were found in less than 50 nucleotides from the transcription start site, whereas more than $12 \%$ and $15 \%$ of these sequences (18,407 and 20,825 cases) were present in 100 nucleotides upstream of the site, respectively. The contribution

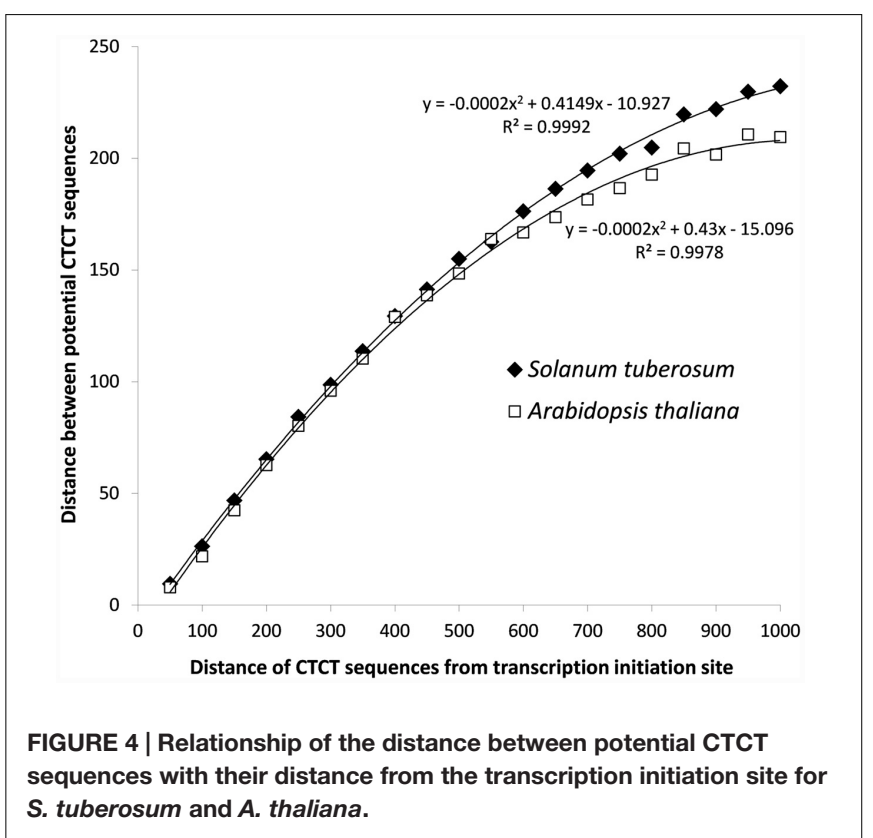

of these motifs decreases rapidly at 150 bp from the start transcription site (Figure 2).

In addition to that, the analysis of distances between potential EMRE sequences that were found in promoter regions indicated 
that many of these sequences are closely packed (Figure 3). The average distance between these motifs is 162 and $146 \mathrm{bp}$ for S. tuberosum and A. thaliana, whereas between these motifs randomly distributed across the promoters much larger, i.e., 271 and 226 bp, respectively. In 36,165 and 40,610 cases (33 and $39 \%)$ in S. tuberosum and A. thaliana, the distance was less than 50 nucleotides, whereas in 3582 and 4757 cases (3.3 and $4.5 \%$ ), respectively, the sequences were adjacent to each other. If we randomized position of these motifs within their promoter regions, only $0.11 \%$ and $0.15 \%$ of distances between these motifs were shorter than 50 bp for S. tuberosum and A. thaliana, and none sequences were adjacent. About 19\% and 23\% distances up to $20 \mathrm{bp}$ were found for the Solanum and Arabidopsis genomes, whereas $0.04 \%$ and $0.01 \%$ for the corresponding randomized data (Figure 3, inset). Interestingly, the densely packed CTCT motifs accumulated close to the site of transcription initiation. A clear positive but non-linear relationship can be observed between the distance of potential EMRE sequences and the distance of these sequences from the transcription initiation site (Figure 4); the closer the motifs to the transcription initiation site, the smaller distances between these motifs in the studied plants.
To check if the potential EMRE motifs occurred in these promoters by chance, we calculated the expected number of these motifs for each promoter region based on the nucleotide composition of the given promoter sequence and compared the expected number with the observed number of CTCT sequences in this promoter. These sequences occurred four times more often than expected in 126 S. tuberosum and 159 A. thaliana promoters and three times more often than expected in 728 S. tuberosum and $975 \mathrm{~A}$. thaliana promoters. However, the excess of the found motifs was statistically significant, with a nominal $p$-value $<0.05$, only in 131 for potato and 236 thale cress promoters. When the Benjamini-Hochberg correction for multiple testing was applied, the difference was statistically significant, with an adjusted $p$-value $<0.05$ only in 12 potato and four thale cress cases.

The top genes with the largest $(>20)$ number of potential EMRE motifs found in their promoters are listed in Tables 1 and 2 . If the MF response is positively correlated with the number of these motifs, then the expression of these genes would be potentially regulated by MFs. In S. tuberosum, there are some genes with extremely large numbers of the motifs but

TABLE 1 | Top Solanum tuberosum genes with the largest number of CTCT motifs found in their promoter regions.

\begin{tabular}{|c|c|c|c|c|c|}
\hline Motifs' number & O/E & Nominal $p$-value & Adjusted $p$-value & $\begin{array}{l}\text { Locus identifier } \\
\text { PGSC0003DMG }\end{array}$ & Gene model description \\
\hline 195 & 4.8 & $2.7 \times 10^{-26}$ & $1.1 \times 10^{-21}$ & 402023823 & Conserved gene of unknown function \\
\hline 162 & 5.6 & $1.1 \times 10^{-23}$ & $2.2 \times 10^{-19}$ & 400036968 & Conserved gene of unknown function \\
\hline 147 & 6.0 & $3.4 \times 10^{-22}$ & $4.7 \times 10^{-18}$ & 400008659 & $\mathrm{RHO}$-related protein from plants 9 (ROP) \\
\hline 126 & 6.2 & $2.8 \times 10^{-19}$ & $2.9 \times 10^{-15}$ & 400036183 & Conserved gene of unknown function \\
\hline 94 & 6.0 & $3.4 \times 10^{-14}$ & $2.8 \times 10^{-10}$ & 400006442 & $\begin{array}{l}\text { Chlorophyll A-B binding family protein; early light } \\
\text { inducible }\end{array}$ \\
\hline 75 & 3.7 & $1.6 \times 10^{-08}$ & $8.3 \times 10^{-05}$ & 400011588 & $\begin{array}{l}\text { RING/FYVE/PHD zinc finger superfamily protein; } \\
\text { inhibitor of growth }\end{array}$ \\
\hline 69 & 3.6 & $1.1 \times 10^{-07}$ & 0.0004 & 400013655 & $\begin{array}{l}\text { Zinc finger (CCCH-type/C3HC4-type RING finger) } \\
\text { family protein, } 113 \mathrm{~A}\end{array}$ \\
\hline 65 & 3.9 & $9.3 \times 10^{-08}$ & 0.0003 & 400042564 & Gene of unknown function \\
\hline 59 & 6.7 & $1.2 \times 10^{-09}$ & $7.3 \times 10^{-06}$ & 400032782 & S-domain-2 5; S-receptor kinase \\
\hline 57 & 8.1 & $4.8 \times 10^{-10}$ & $3.3 \times 10^{-06}$ & 400029702 & Telomerase activating protein Est1; Smg-7 \\
\hline 52 & 5.5 & $7.7 \times 10^{-08}$ & 0.0003 & 400006299 & Gene of unknown function \\
\hline 42 & 9.9 & $4.5 \times 10^{-08}$ & 0.0002 & 400004251 & Stress responsive alpha-beta barrel domain protein \\
\hline 27 & 2.7 & 0.0074 & 1.0000 & 400009231 & $\begin{array}{l}\text { Transducin/WD40 repeat-like superfamily protein; } \\
\text { eukaryotic translation initiation factor } 3 \text { subunit }\end{array}$ \\
\hline 24 & 3.1 & 0.0065 & 1.0000 & 400027515 & $\begin{array}{l}\text { Rhodanese/cell cycle control phosphatase } \\
\text { superfamily protein; Cdc25 }\end{array}$ \\
\hline 24 & 2.1 & 0.0485 & 1.0000 & 400030089 & Heat-shock protein 70T-2; 70kD \\
\hline 23 & 3.4 & 0.0046 & 1.0000 & 400012860 & Extracellular ligand-gated ion channel \\
\hline 23 & 3.1 & 0.0074 & 1.0000 & 400001100 & Electron transfer flavoprotein alpha; oxidoreductase \\
\hline 23 & 3.0 & 0.0087 & 1.0000 & 400025959 & Pentatricopeptide (PPR) repeat-containing protein \\
\hline 22 & 4.2 & 0.0024 & 1.0000 & 400013826 & Early flowering 3 \\
\hline 21 & 3.3 & 0.0083 & 1.0000 & 400041921 & Gene of unknown function \\
\hline 21 & 3.2 & 0.0093 & 1.0000 & 400030537 & $60 S$ ribosomal protein L31e family protein \\
\hline 21 & 3.1 & 0.0122 & 1.0000 & 400035125 & Gene of unknown function \\
\hline 21 & 2.9 & 0.0148 & 1.0000 & 400044565 & Gene of unknown function \\
\hline 21 & 2.6 & 0.0244 & 1.0000 & 400023145 & Pentatricopeptide (PPR) repeat-containing protein \\
\hline 21 & 2.6 & 0.0256 & 1.0000 & 400029893 & Gene of unknown function \\
\hline
\end{tabular}

O/E is the ratio of the observed to the expected number of motifs in their promoters. 
their function is unknown, whereas in the case of $A$. thaliana, more than one-third of these genes constitute transposable elements. The promoter for the potato gene encoding RHOrelated protein is also rich in CTCT sequences. Such proteins transmit a variety of extracellular and intracellular signals by regulating downstream pathways and signaling cascades. These proteins are involved in diverse cellular processes, such as cytoskeletal organization, pollen and vegetative cell growth, hormone responses, stress responses, and pathogen resistance. Moreover, the motif-rich genes also encode putative transcription factors, proteins interacting with DNA, protein kinases and phosphatases, as well as others, which could regulate the expression of other genes and coded proteins under the influence of MFs. Both plants also express pentatricopeptide (PPR) repeatcontaining proteins, which are expressed in mitochondria and plastids. In these organelles, the PPR repeat-containing proteins bind organellar transcripts and influence their expression by RNA editing, turnover, processing, or translation (Barkan and Small, 2014); consequently, they have profound effects on organelle biogenesis and function, including photosynthesis, respiration, plant development, and environmental responses.

Interestingly, among the $S$. tuberosum genes with the large numbers of potential EMRE motifs are those that code for stress-responsive alpha-beta barrel domain protein and heatshock protein 70T-2 (Table 1). In fact, human HSP70 promoters containing these motifs respond to MFs (Lin et al., 1998, 1999); similarly, we found at least one CTCT motif in the promoters of almost all genes encoding HSP70 in potato (Table 3). More than half of the HSP70 genes have more observed motifs than expected. In the case of $A$. thaliana promoters for HSP70 genes, all contained at least one this motif and almost $90 \%$ of them had more observed these motifs than expected (Table 4).

TABLE 2 | Top A. thaliana genes with the largest number of CTCT motifs found in their promoter regions.

\begin{tabular}{|c|c|c|c|c|c|}
\hline Motifs' number & O/E & Nominal $p$-value & Adjusted $p$-value & Locus identifier & Gene model description \\
\hline 50 & 5.6 & $1.1 \times 10^{-7}$ & 0.0035 & AT2G30740 & Serine/threonine protein kinase \\
\hline 43 & 6.1 & $5.4 \times 10^{-7}$ & 0.0083 & AT3G31406 & Transposable element gene \\
\hline 42 & 4.7 & $5.6 \times 10^{-6}$ & 0.0438 & AT4G04590 & Transposable element gene; CACTA-like transposase family \\
\hline 35 & 5.0 & $2.5 \times 10^{-5}$ & 0.1317 & AT2G12510 & $\begin{array}{l}\text { Transposable element gene; gypsy-like retrotransposon } \\
\text { family }\end{array}$ \\
\hline 33 & 7.6 & $4.7 \times 10^{-6}$ & 0.0438 & AT2G13175 & Transposable element gene; CACTA-like transposase family \\
\hline 32 & 4.7 & $8.7 \times 10^{-5}$ & 0.3872 & AT5G28410 & Unknown protein \\
\hline 31 & 3.1 & $0.0 \times 017$ & 1.0000 & AT1G27870 & Nucleic acid binding \\
\hline 29 & 8.2 & $1.5 \times 10^{-5}$ & 0.0913 & AT1G33350 & Pentatricopeptide (PPR) repeat-containing protein \\
\hline 27 & 4.1 & 0.0007 & 1.0000 & AT3G42060 & Myosin heavy chain-related \\
\hline 26 & 6.3 & 0.0001 & 0.4803 & AT3G47600 & Putative transcription factor (MYB94) \\
\hline 25 & 5.0 & 0.0005 & 1.0000 & AT3G29610 & Transposable element gene \\
\hline 25 & 4.9 & 0.0005 & 1.0000 & AT3G55960 & NLI interacting factor (NIF) family protein \\
\hline 25 & 3.5 & 0.0028 & 1.0000 & AT1G44060 & Transposable element gene; CACTA-like transposase family \\
\hline 24 & 3.5 & 0.0035 & 1.0000 & AT3G13140 & Hydroxyproline-rich glycoprotein family protein \\
\hline 23 & 5.6 & 0.0005 & 1.0000 & AT1G63480 & DNA-binding family protein \\
\hline 23 & 5.0 & 0.0009 & 1.0000 & AT5G58550 & $\begin{array}{l}\text { Paralog of ETO1, a negative regulator of ACS5 involved in } \\
\text { ethylene biosynthesis pathway }\end{array}$ \\
\hline 23 & 4.2 & 0.0019 & 1.0000 & AT1G36403 & Transposable element gene; mutator-like transposase family \\
\hline 23 & 2.5 & 0.0256 & 1.0000 & AT2G11620 & Unknown protein \\
\hline 22 & 4.0 & 0.0029 & 1.0000 & AT3G51390 & Zinc finger (DHHC type) family protein \\
\hline 22 & 3.6 & 0.0050 & 1.0000 & AT5G35066 & Unknown protein \\
\hline 22 & 2.7 & 0.0189 & 1.0000 & AT3G30837 & Transposable element gene; CACTA-like transposase family \\
\hline 22 & 2.0 & 0.0827 & 1.0000 & AT1G10330 & Pentatricopeptide (PPR) repeat-containing protein \\
\hline 21 & 5.5 & 0.0011 & 1.0000 & AT2G28350 & Involved in root cap cell differentiation \\
\hline 21 & 4.3 & 0.0028 & 1.0000 & AT1G50620 & PHD finger family protein \\
\hline 21 & 4.2 & 0.0031 & 1.0000 & AT3G42130 & Glycine-rich protein \\
\hline 21 & 2.9 & 0.0152 & 1.0000 & AT5G28320 & Unknown protein \\
\hline 21 & 2.5 & 0.0329 & 1.0000 & AT3G43154 & $\begin{array}{l}\text { Transposable element gene; pseudogene, hypothetical } \\
\text { protein }\end{array}$ \\
\hline 21 & 2.2 & 0.0610 & 1.0000 & AT2G34130 & Transposable element gene; CACTA-like transposase family \\
\hline 21 & 2.1 & 0.0703 & 1.0000 & AT5G30762 & $\begin{array}{l}\text { Transposable element gene; pseudogene, hypothetical } \\
\text { protein }\end{array}$ \\
\hline 21 & 1.6 & 0.2117 & 1.0000 & AT5G32511 & $\begin{array}{l}\text { Transposable element gene; pseudogene, hypothetical } \\
\text { protein }\end{array}$ \\
\hline
\end{tabular}

O/E is the ratio of the observed to the expected number of motifs in their promoters. 
TABLE 3 | Solanum tuberosum HSP70-encoding genes with the number of СTCT motifs found in their promoter regions.

\begin{tabular}{|c|c|c|}
\hline Motifs' number & O/E & Locus identifier PGSC0003DMG \\
\hline 24 & 2.1 & 400030089 \\
\hline 12 & 3.1 & 402031379 \\
\hline 10 & 2.4 & 400012254 \\
\hline 7 & 1.6 & 400015920 \\
\hline 5 & 2.4 & 400024707 \\
\hline 5 & 1.7 & 400018544 \\
\hline 5 & 1.5 & 400028634 \\
\hline 5 & 1.2 & 401031379 \\
\hline 4 & 1.9 & 400030089 \\
\hline 4 & 1.7 & 400000398 \\
\hline 4 & 1.6 & 400024707 \\
\hline 4 & 1.5 & 400003246 \\
\hline 4 & 1.1 & 400003122 \\
\hline 3 & 1.5 & 400008917 \\
\hline 3 & 1.0 & 400003246 \\
\hline 3 & 0.9 & 400014212 \\
\hline 3 & 0.9 & 400014212 \\
\hline 2 & 0.8 & 400010677 \\
\hline 2 & 0.8 & 400024887 \\
\hline 2 & 0.6 & 400010677 \\
\hline 2 & 0.6 & 400044451 \\
\hline 2 & 0.5 & 400011197 \\
\hline 1 & 0.5 & 400028634 \\
\hline 1 & 0.4 & 400008698 \\
\hline 1 & 0.3 & 401031379 \\
\hline 0 & 0.0 & 400003122 \\
\hline
\end{tabular}

$\mathrm{O} / \mathrm{E}$ is the ratio of observed to expected number of motifs in their promoters.

To look for the elements that could modulate transcription in response to ELF-MF, we further analyzed the sequences of three potato promoters, namely 16R, 20R, and 5UGT. These promoters are well-studied and validated expression models in plants (Korobczak et al., 2005; Łukaszewicz and Szopa, 2005).

\section{4-3-3 Protein 16R Promoter}

Within the 16R promoter (972 nucleotides in length), the transcription initiation site is located 89 nucleotides upstream of the translation initiation site. This promoter region contains a typical CCAAT box, located at position -147, but lacks a typical TATA box. Among many others, the following putative transcription factor binding sites were found in this promoter: ARF (Auxin Response Factor), light-regulated element GATA, I-box, GT1, elicitor responsive element (ElRE) regulated upon response to infection (TTGACC), and a frequent motif, AATAGAAAA, present in promoters of genes regulated by sucrose levels. Three CTCT motifs were found, which could potentially regulate gene expression after exposure to MFs.

Sucrose and plant hormones (such as IAA, ABA, and salicylic acid) regulated the expression of GUS under control of the 16R promoter (Szopa et al., 2003b). The fastest-acting factor was salicylic acid (2- to 3 -fold increase in $6 \mathrm{~h}$ after stimulation). The
TABLE 4 | Arabidopsis thaliana HSP70-encoding genes with the number of CTCT motifs found in their promoter regions.

\begin{tabular}{lcc}
\hline Motifs' number & O/E & Locus identifier \\
\hline 11 & 3.0 & AT1G79920 \\
9 & 2.1 & AT4G16660 \\
9 & 2.6 & AT5G02500 \\
8 & 2.0 & AT4G24280 \\
6 & 1.5 & AT3G09440 \\
6 & 1.5 & AT5G09590 \\
5 & 2.3 & AT1G79930 \\
5 & 1.3 & AT1G11660 \\
5 & 1.8 & AT2G32120 \\
5 & 1.6 & AT3G12580 \\
5 & 1.5 & AT4G17750 \\
5 & 1.3 & AT5G02490 \\
4 & 1.7 & AT1G16030 \\
3 & 1.0 & AT4G37910 \\
3 & 1.7 & AT4G32208 \\
2 & 0.7 & AT1G09080 \\
1 & 0.3 & AT5G49910 \\
\hline
\end{tabular}

$\mathrm{O} / \mathrm{E}$ is the ratio of observed to expected number of motifs in their promoters.

strongest influence on 16R promoter activity was observed in the case of IAA (after $24 \mathrm{~h}$, sevenfold induction), while there was no statistically significant effect of the $50-\mathrm{Hz}$ MF with $60-70 \mathrm{~A} / \mathrm{m}$ intensity (Figure 5).

\section{4-3-3 Protein 20R Promoter}

The 20R promoter (1239 nucleotides in length) contains a number of motifs that potentially respond to light, amylase boxes, and sequences regulated by ABA and cold (Aksamit et al., 2005). Fewer sequences are potentially responsible for regulation by auxins, salicylic acid, pathogens, sucrose, or ethylene. Within the analyzed promoter, a transcriptional activator involved in flavonoid biosynthesis regulation was also found. Finally, a motif regulated by metals in the mouse gene encoding the murine metallothionein (Koizumi et al., 1999) was identified. Twelve CTCT motifs were also recognized in the promoter.

Different factors were tested using this promoter: ABA, ethylene, auxin, salicylic acid, pathogen infections, metals (cadmium, zinc, and copper), salt, glycol, light, wounding, low temperature, and sucrose. Auxin, ethylene, salicylic acid, pathogen infection, and sucrose did not affect GUS activity (Aksamit et al., 2005); however, ABA, cold, light, and heavy metals did regulate GUS expression. The strongest influence on the 20R promoter's activity (eightfold induction) was observed in the case of zinc stress after $24 \mathrm{~h}$; the $50-\mathrm{Hz} \mathrm{MF}$ had no statistically significant effect on the activity of the 20R promoter (Figure 6). Additionally, to exclude impact of mechanical stress an experiment was performed on 14-days whole potato plants (Figure 7). In the leaves of plants exposed to EMF, no statistically significant increase in GUS activity was observed $6 \mathrm{~h}$ after the exposition. The activity decreased in the following time-points and was similar to the control. 


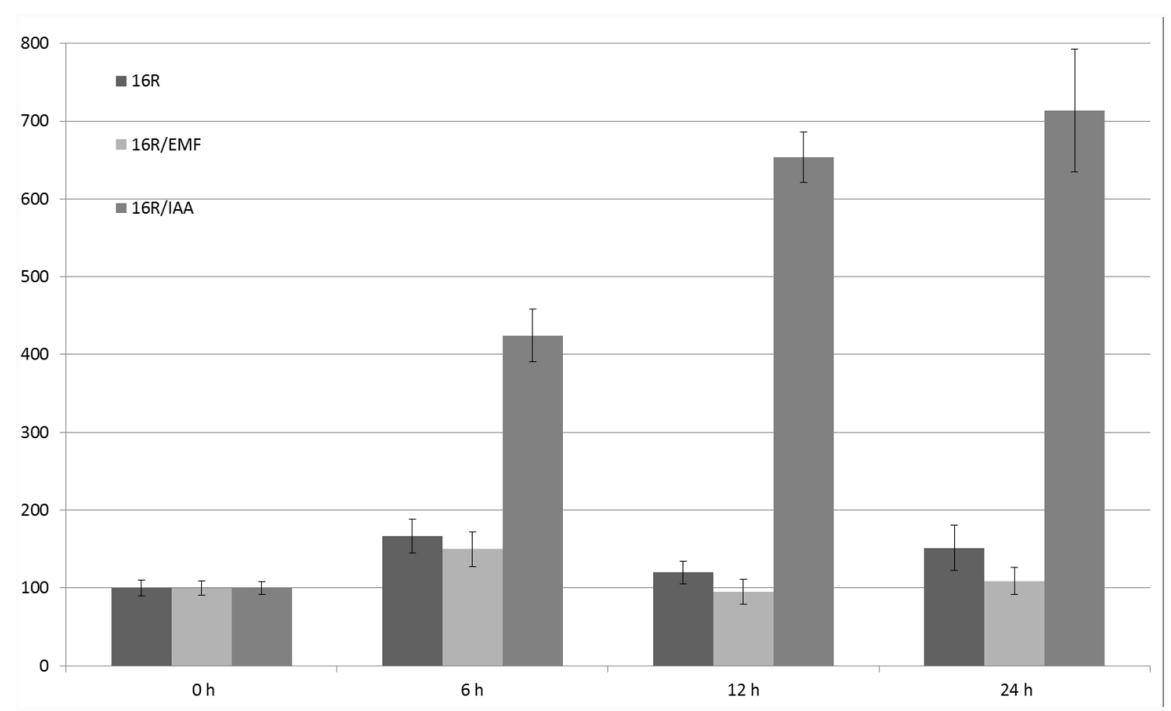

FIGURE 5 | Regulation of expression of $16 R$ promoter under the influence of extremely low-frequency magnetic field (EMF) and IAA. The activity of $\beta$-glucuronidase (GUS) in the leaves was measured at the start of the experiment $(0 \mathrm{~h})$ and after 6,12 , and $24 \mathrm{~h}$. Young leaves of potatoes grown in the greenhouse were cut (in four parts) and incubated in MS medium (control), under MF 61-69 A/m, or with $100 \mu \mathrm{M}$ IAA. The graph shows the mean values and confidence intervals obtained from 31 replicates. GUS activity in the control was assumed as 100\%.

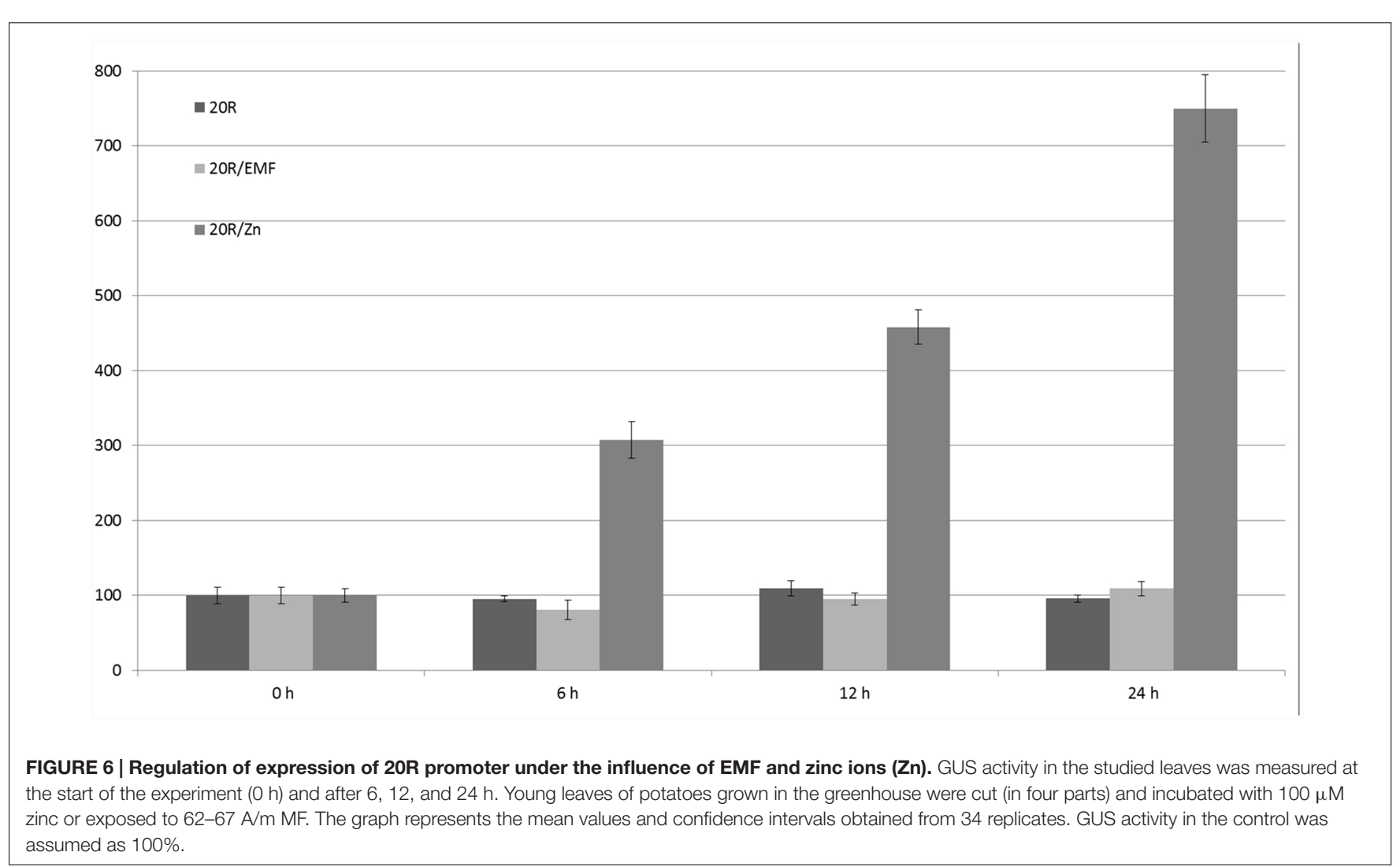

\section{Glucosyltransferase (5UGT) Promoter}

The glucosyltransferase promoter (1625 nucleotides in length) was isolated from the wild potato S. sogarandinum. Within its entire sequence, several motifs were found upstream of the translation start site that are potentially recognized by transcription factors and involved in the regulation of responses to UV light, ABA, light, sucrose, and potentially MF because five CTCT motifs were identified. Using heterologous expression in 


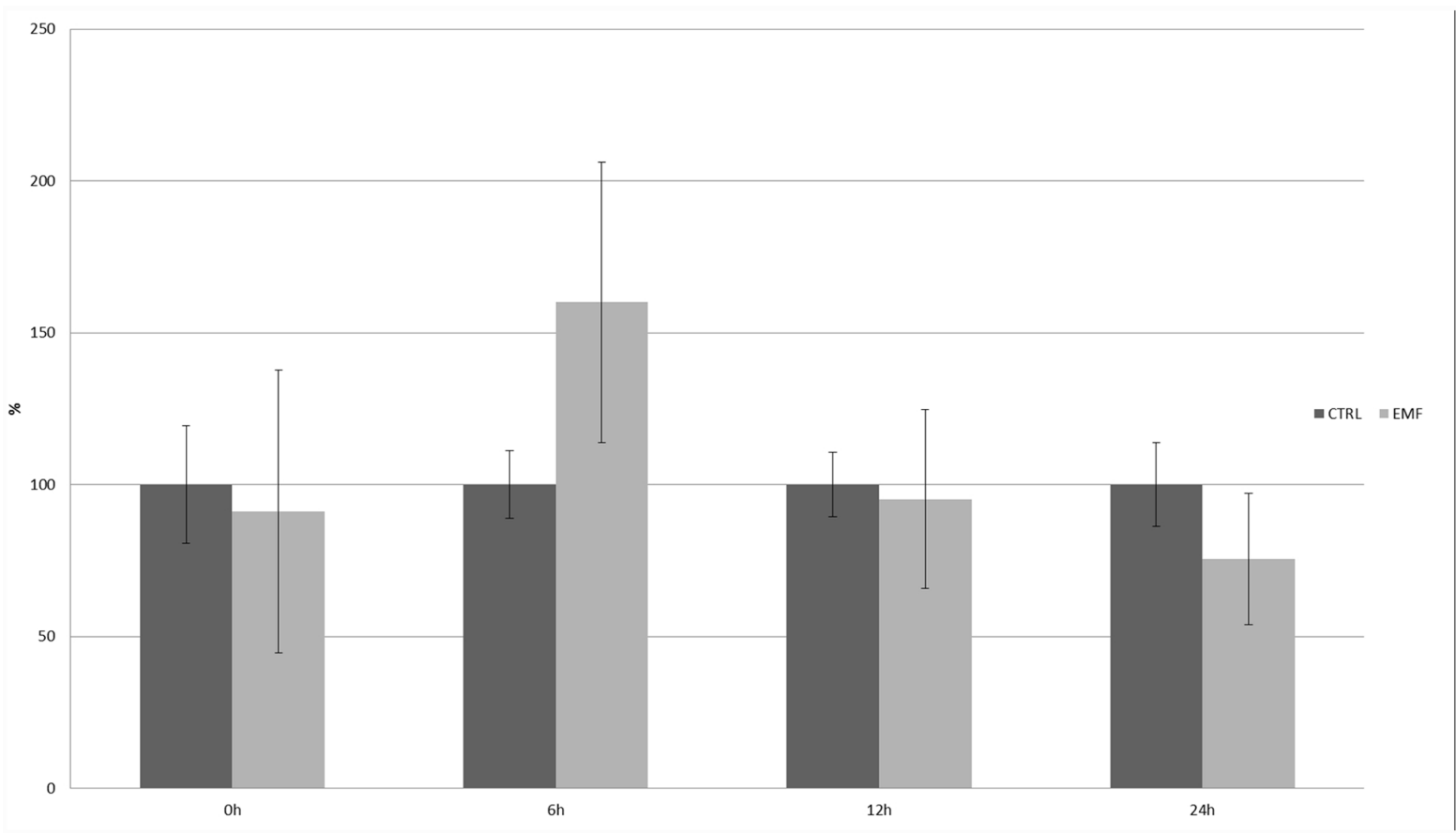

FIGURE 7 | Expression of 20R promoter under the influence of EMF after $30 \mathrm{~min}$ exposition of whole 14 day old potato plants. GUS activity in the studied leaves was measured at the start of the experiment $(0 \mathrm{~h})$ and after 6,12 , and $24 \mathrm{~h}$. The graph represents the mean values and confidence intervals obtained from three replicates. GUS activity at the start of the experiment $(\mathrm{O} \mathrm{h})$ in the control was assumed as $100 \%$.

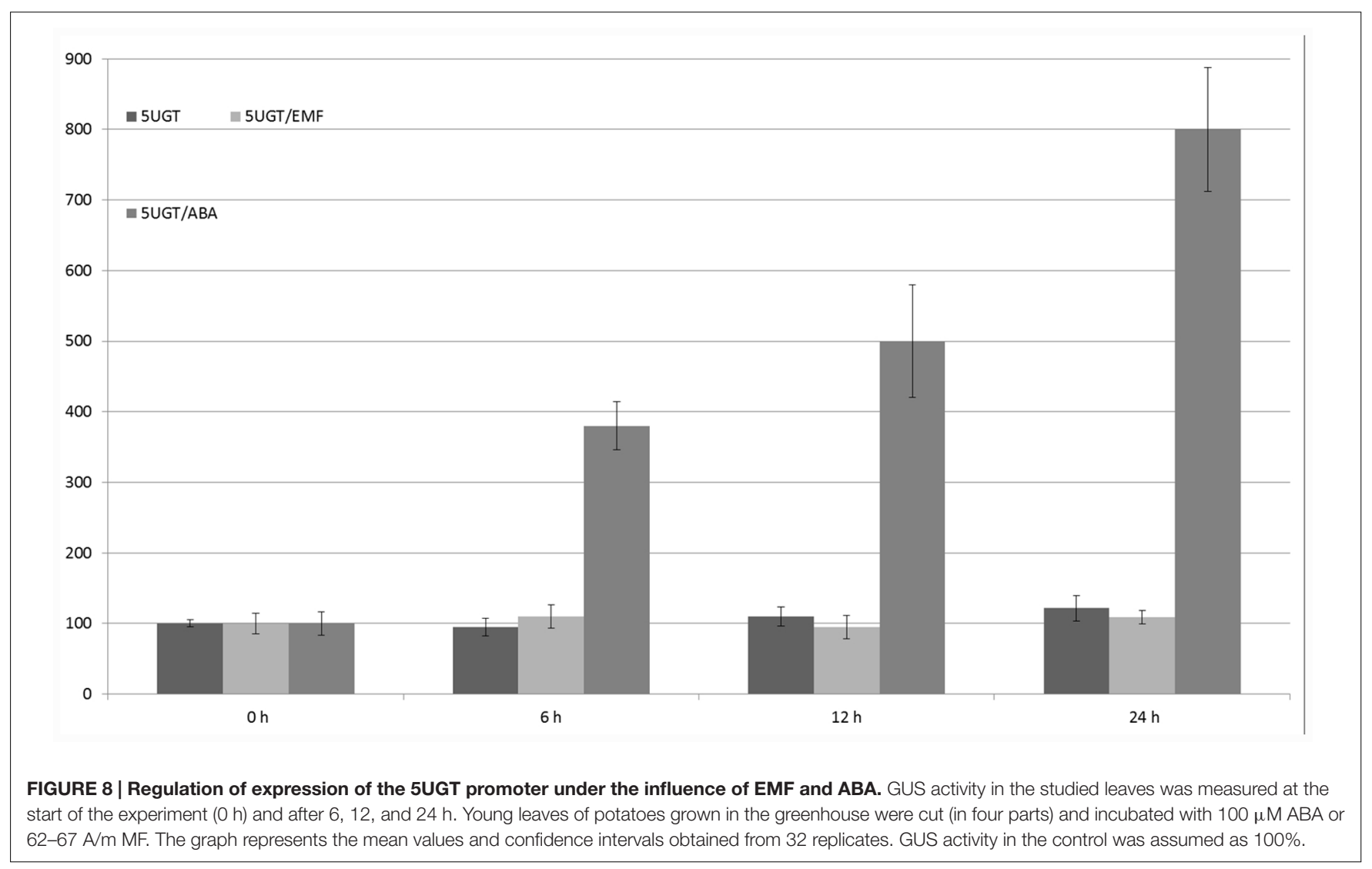


S. tuberosum, the 5UGT promoter was induced by UV light, cold, light, $\mathrm{ABA}$, and salt $(\mathrm{NaCl})$. The effect of cooling and light, as well as ABA and cold, were synergistic. The 5UGT promoter's activity was inhibited by sugar concentrations above $2 \%$ (LorencKukuła et al., 2004). The 5UGT promoter's activity increased with time while under the influence of ABA was the highest (eightfold) after $24 \mathrm{~h}$ of incubation. However, there was no statistically significant effect of the $50-\mathrm{Hz} \mathrm{MF}$ with $60-70 \mathrm{~A} / \mathrm{m}$ intensity (Figure 8). This result was also confirmed in $S$. sogarandinum by mRNA (qPCR) and protein (Western Blot) quantification (Supplementary Figures S2, S3).

\section{DISCUSSION}

It was postulated that MFs may affect DNA by moving charges (Blank and Goodman, 1999). In agreement with that, the movement of electrons in DNA was observed (Wan et al., 1999; Porath et al., 2000). Moreover, it was suggested that conduction in DNA depends on its structure (Meggers et al., 1998). Therefore, it is reasonable to assume that MFs could interact preferentially with some specific DNA sequences. It was assumed that, three CTCT sequences (EMREs) in the human $h s p 70$ and $c-m y c$ promoters regulate expression in response to $\mathrm{MF}$ exposure for $30 \mathrm{~min}$ at $60 \mathrm{~Hz}$ and $8 \mu \mathrm{T}$ (Lin et al., 1997, 1998, $1999,2001)$. Although, such response to magnetic flux density $(8 \mu \mathrm{T}=10 \mathrm{~A} / \mathrm{m})$ is below the upper limit $(60 \mathrm{~A} / \mathrm{m})$ regarded as safe (Zmyslony et al., 2005), these values are frequently measured in households, especially those under overhead power lines (Vulevic and Osmokrovic, 2011). We have previously shown that some transcriptionally active motifs within promoters could be conserved across plant and animal taxa, for example, those induced by metals (Aksamit et al., 2005).

Thus, the purpose of this study was to evaluate the hypothesis that $60 \mathrm{~A} / \mathrm{m}$ alternating MF may regulate plant gene expression through CTCT motifs. First, we analyzed how often this motif occurred in promoters throughout the genome of $S$. tuberosum and the model plant $A$. thaliana. After examining more than 40,000 in $S$. tuberosum and 30,000 in A. thaliana potential promoters and, with lengths of 1000 nucleotides, we found, about 150,000 in S. tuberosum and 130,000 in A. thaliana putative EMRE motifs appearing within the analyzed promoters, about four times on average. Such a high frequency of potential EMRE motif would suggest that this element alone could not be responsible for the precise regulation of gene expression in response to the given factor (e.g., a $50-\mathrm{Hz} \mathrm{MF}$ ). This could partially explain previous failures to obtain repeatable effects (Heredia-Rojas et al., 2010; Buchachenko, 2016) and supports the hypothesis that additional elements should assist in changing expression in response to MFs.

Although our searches revealed that the CTCT motifs are widely distributed in the studied plant genomes, the conserved test verifying their presence by chance in promoter regions based on their general nucleotide composition showed only 12 and 4 significant cases for S. tuberosum and A. thaliana, respectively. However, this statistical procedure tests only the presence CTCT motifs but not their arrangements. Our detailed analyses demonstrated that the CTCT sequences are not randomly distributed within promoter regions but are usually located near the transcription initiation site, where they form clusters, i.e., are laid in a very close distance to each other. The majority of these motifs (about 3582 in S. tuberosum and 4757 in $A$. thaliana) are adjoining. The organization of these motifs in clusters may suggest some regulation of gene expression, involving the cooperative binding of transcription factors to DNA. Moreover, it cannot be excluded that some of the neighboring stretches of CTCT were generated by CT dinucleotide repeat expansion, e.g., by DNA polymerase slippage mutations. The distribution of CTCT sequences may be also influenced by genome rearrangements and amplifications mediated by transposable elements (Bennetzen, 2000; Fedoroff, 2000; Feschotte and Pritham, 2007), because these motifs were often found near such elements (Tables 1 and 2).

However, the non-random distribution and composition of these motifs suggests that many of them overlap or are placed within so-called GAGA elements, which consist of dinucleotide repeats with the pattern $(\mathrm{GA})_{n} /(\mathrm{TC})_{\mathrm{n}}$. These elements are a target for specific protein complexes, replacing nucleosomes to create a local chromatin environment, which enables a variety of regulatory responses (Lehmann, 2004). GAGA elements can also be related to the epigenetic regulation of homeotic genes and may influence the promoter-proximal pausing of RNA polymerase II (Lehmann, 2004; Fujioka et al., 2008; Lee et al., 2008; Vaquero et al., 2008). Although the GAGA elements were usually studied in Drosophila melanogaster in the context of the regulation of numerous developmental genes (Lehmann, 2004), such motifs and the proteins interacting with them were also characterized in plants (Sangwan and O’Brian, 2002; Santi et al., 2003; Meister et al., 2004; Roig et al., 2004; Kooiker et al., 2005; Wanke et al., 2011). Because the expression pattern of these proteins, designated as BBR/BPC, is widespread and their potential target DNA motifs are also numerous in plant genomes, it seems that these factors may influence the expression of various genes involved in different plant processes, in addition to homeobox genes.

The transcriptional activation by GAGA factors and the presence of GAGA elements in promoter regions were also reported for $h s p 70$ genes (Granok et al., 1995; Wilkins and Lis, 1997; Georgel, 2005). Interestingly, human HSP70 promoters include CTCT motifs that respond to MFs (Lin et al., 1998, 1999). Our analysis of potential promoters in almost all S. tuberosum and all $A$. thaliana $h s p 70$ genes also revealed the presence of such motifs, which would suggest that the expression of these genes could be regulated by MFs (Table 2). Other genes (e.g., those encoding putative transcription factors, pentatricopeptide repeat-containing proteins, or $\mathrm{RHO}$-related protein) may be also considered MF-sensitive because their promoters contain a significant number of CTCT motifs (Tables 1 and 2).

It would be worthwhile to reproduce an easy experimental system to study the impact of MFs on living organisms, including plants. Therefore, in addition to the statistical evaluation of plant promoters, we tested the impact of MFs on stress-related promoters in S. tuberosum; however, in the studied experimental conditions, there was no significant regulatory effect of the $50-\mathrm{Hz}$ 
$\mathrm{MF}$ in the range of $60-70 \mathrm{~A} / \mathrm{m}$ on the expression of $14-$ 3-3 protein gene promoters (16R and 20R) or the glucose 5UGT transferase promoter. Besides the assumption that the EMRE does exist but plants do not respond to MFs because of inappropriate parameters used in the experiments, there are several other possible explanations. One of them is that the CTCT sequences that might act as EMREs should be separated by specific distances. It is also possible that the presence of other motifs and interactions between various transcription factors are necessary for ELF-MF perception, which is very common in many regulators of gene expression. In addition to other uncontrolled parameters that lead to cell line-dependent construct expression, there are clear experimental differences between animal (Jin et al., 1997) and plant (Michelet et al., 1994) cells. In the animal cell experiments, EMF stimuli of less than $1 \mu \mathrm{T}$ elicited transcripts within $5 \mathrm{~min}$, stress proteins within $20 \mathrm{~min}$, and synthesis gradually decreased after about $3 \mathrm{~h}$. In this work the 30 min EMF stimuli was evaluated after 6, 12, and $24 \mathrm{~h}$. Plants are usually grown in laboratories in temperature about $20^{\circ} \mathrm{C}$ lower than that in animal cells. Therefore, cellular responses, according to the Arrhenius equation, would be roughly fourfold slower in plant cells incubated in $18^{\circ} \mathrm{C}$ than in animal cells in $37^{\circ} \mathrm{C}$. Consequently, stress responses in plants are often much slower than in animals, with the highest level of reporter proteins occurring often after $24 \mathrm{~h}$ (Figures 5-7). Indeed, in plant cells, the production of proteins on onceproduced mRNA template may be constant for at least $6 \mathrm{~h}$, resulting in steady accumulation of a reporter protein. Once produced and accumulated, the reporter protein, such as GUS, is relatively stable and may be detected for several hours after translation. Consequently, even very short transcriptional activation should be visible in our experimental conditions except for very weak activation, resulting in signal lower than background.

The presented results did not confirm the hypothesis that CTCT motifs are EMREs in the studied plant promoters, which seemed promising because they contain CTCT motifs and are known to response to stress conditions. Although we observed no significant response to MF in the plant model, it cannot be excluded that other promoters or motifs can fulfill such function. Moreover, the response can be realized by a complex regulatory network that escapes the simple promoter studies. The response could be initiated by a subset of genes whose promoters can have some MF-specific motifs. Products of these genes could further serve as transcription factors for many other genes whose promoters may not have such specific motifs. These genes may not give positive response to MF if other set of regulated genes are not sufficiently expressed. This complicated network regulation of gene expression requires a separate approach to particular cases and selection of the promoters to GUS/GFP studies without

\section{REFERENCES}

Aksamit, A., Korobczak, A., Skala, J., Łukaszewicz, M., and Szopa, J. (2005). The 14-3-3 gene expression specificity in response to stress is promoter-dependent. Plant Cell Physiol. 46, 1635-1645. doi: 10.1093/pcp/ pci179 additional knowledge would be misleading. On the other hand, widespread criticism of the original paper about the presence of EMREs, suggests that such elements do not exists in plants. Therefore, the analysis of promoter regions at the specific genes requires a special and separate consideration.

\section{AUTHOR CONTRIBUTIONS}

MŁ, DS: study concept and design, data acquisition, statistical analysis, analysis and interpretation, manuscript drafting, editing and revision, manuscript final version approval, PM: data acquisition, statistical and bioinformatic analyses, analysis and interpretation of results, manuscript drafting, editing and revision, manuscript final version approval, AA-S: data acquisition, analysis and interpretation, manuscript final version approval, KK: data acquisition, analysis, and interpretation.

\section{FUNDING}

This work was supported by Wrocław Centre of Biotechnology, program: The Leading National Research Centre (KNOW) for years 2014-2018 (www.know.wroc.pl).

\section{ACKNOWLEDGMENT}

Special thanks to Magdalena Żuk for plants maintenance and to Jan Szopa for fruitful discussion.

\section{SUPPLEMENTARY MATERIAL}

The Supplementary Material for this article can be found online at: http://journal.frontiersin.org/article/10.3389/fpls.2017.00178/ full\#supplementary-material

FIGURE S1 | Exposure system from the top (A) and side (B). Orientation of leaf's stem against the force lines of magnetic field generated in exposure system. C1, C2, coils; L, magnetic field exposed leaf; P-base, structural elements supporting Helmholtz coils; W, force lines of magnetic field; S-Petri dish with the exposed sample.

FIGURE S2 | Western analysis of proteins isolated from leaves of control and treated S. sogarandinum plants. $80 \mu \mathrm{g}$ of protein was applied onto each slot of SDS-polyacrylamide gel electrophoresis and the blot was probed with antibody anti-recombinant GT protein. The treatment conditions are marked over the result of western analysis. C1 and C2- control (untreated sample), samples with 30-min treatment in the magnetic field 62-67 A/m and collected after $6 \mathrm{~h}(6 / 1$, 6/2, 6/3, 6/4), 12 h (12/1, 12/2, 12/3, 12/4), and 24 h (24/1, 24/2, 24/3, 24/4).

FIGURE S3 | Quantification of GT gene expression by real time PCR in S. sogaradinum in response to MF exposition after $0,6,12$, and $24 \mathrm{~h}$. 
Benjamini, Y., and Hochberg, Y. (1995). Controlling the false discovery rate: a practical and powerful approach to multiple testing. J. R. Stat. Soc. Ser. B Methodol. 57, 289-300.

Bennetzen, J. L. (2000). Transposable element contributions to plant gene and genome evolution. Plant Mol. Biol. 42, 251-269. doi: 10.1023/a:1006344508454

Blank, M., and Goodman, R. (1999). Electromagnetic fields may act directly on DNA. J. Cell. Biochem. 75, 369-374. doi: 10.1002/(SICI)1097-4644(19991201) 75:3<369::AID-JCB2>3.0.CO;2-A

Blank, M., and Goodman, R. (2011a). Comments on DNA as a fractal antenna reply. Int. J. Radiat. Biol. 87, 1209-1209.

Blank, M., and Goodman, R. (2011b). DNA is a fractal antenna in electromagnetic fields. Int. J. Radiat. Biol. 87, 409-415. doi: 10.3109/09553002.2011.538130

Bradford, M. (1976). A rapid and sensitive method for the quantitation of microgram quantities of protein utilizing the principle of protein-dye binding. Anal. Biochem. 72, 248-254. doi: 10.1016/0003-2697(76)90527-3

Buchachenko, A. (2016). Why magnetic and electromagnetic effects in biology are irreproducible and contradictory? Bioelectromagnetics 37, 1-13. doi: 10.1002/ bem. 21947

D'Angelo, C., Costantini, E., Kamal, M. A., and Reale, M. (2015). Experimental model for ELF-EMF exposure: concern for human health. Saudi J. Biol. Sci. 22, 75-84. doi: 10.1016/j.sjbs.2014.07.006

Fedoroff, N. (2000). Transposons and genome evolution in plants. Proc. Natl. Acad. Sci. U.S.A. 97, 7002-7007. doi: 10.1073/pnas.97.13.7002

Feschotte, C., and Pritham, E. J. (2007). DNA transposons and the evolution of eukaryotic genomes. Annu. Rev. Genet. 41, 331-368. doi: 10.1146/annurev. genet.40.110405.090448

Foster, K. R. (2011). Comments on DNA as a fractal antenna. Int. J. Radiat. Biol. 87, 1208-1209. doi: 10.3109/09553002.2011.626490

Fujioka, M., Yusibova, G. L., Zhou, J., and Jaynes, J. B. (2008). The DNA-binding Polycom $\beta$-group protein Pleiohomeotic maintains both active and repressed transcriptional states through a single site. Development 135, 4131-4139. doi: $10.1242 /$ dev.024554

Georgel, P. T. (2005). Chromatin potentiation of the hsp70 promoter is linked to GAGA-factor recruitment. Biochem. Cell Biol. 83, 555-565. doi: 10.1139/ o05-060

Goodstein, D. M., Shu, S., Howson, R., Neupane, R., Hayes, R. D., Fazo, J., et al. (2012). Phytozome: a comparative platform for green plant genomics. Nucleic Acids Res. 40, D1178-D1186. doi: 10.1093/nar/gkr944

Granok, H., Leibovitch, B. A., Shaffer, C. D., and Elgin, S. C. R. (1995). Chromatin: ga-ga over GAGA factor. Curr. Biol. 5, 238-241. doi: 10.1016/s0960-9822(95) 00048-0

Heredia-Rojas, J. A., de la Fuente, A. O. R., Gonzalez, J. M. A., Rodriguez-Flores, L. E., Rodriguez-Padilla, C., Santoyo-Stephano, M. A., et al. (2010). Effect of 60 $\mathrm{Hz}$ magnetic fields on the activation of hsp70 promoter in cultured INER-37 and RMA E7 cells. In Vitro Cell. Dev. Biol. Anim. 46, 758-763. doi: 10.1007/ s11626-010-9342-y

Jefferson, R. A., Kavanagh, T. A., and Bevan, M. W. (1987). GUS fusions: betaglucuronidase as a sensitive and versatile gene fusion marker in higher plants. EMBO J. 6, 3901-3907.

Jin, M., Lin, H., Han, L., Opler, M., Maurer, S., Blank, M., et al. (1997). Biological and technical variables in myc expression in HL60 cells exposed to $60 \mathrm{~Hz}$ electromagnetic fields. Bioelectrochem. Bioenerg. 44, 111-120. doi: 10.1016/ s0302-4598(97)00054-8

Koizumi, S., Kaoru, S., Yasumitsu, O., Hirotomo, Y., and Fuminori, O. (1999). Transcriptional activity and regulatory protein binding of metal-responsive element sof human metalothionein-IIa gene. Eur. J. Biochem. 259, 635-642. doi: 10.1046/j.1432-1327.1999.00069.x

Kooiker, M., Airoldi, C. A., Losa, A., Manzotti, P. S., Finzi, L., Kater, M. M., et al. (2005). BASIC PENTACYSTEINE1, a GA binding protein that induces conformational changes in the regulatory region of the homeotic Arabidopsis gene SEEDSTICK. Plant Cell 17, 722-729. doi: 10.1105/tpc.104.030130

Korobczak, A., Aksamit, A., Łukaszewicz, M., Lorenc, K., Rorat, T., and Szopa, J. (2005). The potato glucosyltransferase gene promoter is environmentally regulated. Plant Sci. 168, 339-348. doi: 10.1016/j.plantsci.2004.07.038

Lamesch, P., Berardini, T. Z., Li, D., Swarbreck, D., Wilks, C., Sasidharan, R., et al. (2012). The Arabidopsis information resource (TAIR): improved gene annotation and new tools. Nucleic Acids Res. 40, D1202-D1210. doi: 10.1093/ nar/gkr1090
Lee, C., Li, X., Hechmer, A., Eisen, M., Biggin, M. D., Venters, B. J., et al. (2008). NELF and GAGA factor are linked to promoter-proximal pausing at many genes in Drosophila. Mol. Cell. Biol. 28, 3290-3300. doi: 10.1128/mcb.022 24-07

Lehmann, M. (2004). Anything else but GAGA: a nonhistone protein complex reshapes chromatin structure. Trends Genet. 20, 15-22. doi: 10.1016/j.tig.2003. 11.005

Lin, H., Blank, M., and Goodman, R. (1999). A magnetic field-responsive domain in the human HSP70 promoter. J. Cell. Biochem. 75, 170-176. doi: 10.1002/ (SICI)1097-4644(19991001)75:1<170::AID-JCB17>3.3.CO;2-X

Lin, H., Blank, M., Rossol-Haseroth, K., and Goodman, R. (2001). Regulating genes with electromagnetic response elements. J. Cell. Biochem. 81, 143-148. doi: 10.1002/1097-4644(20010401)81:1<143::AID-JCB1030>3.0.CO;2-4

Lin, H., Head, M., Blank, M., Han, L., Jin, M., and Goodman, R. (1998). Mycmediated transactivation of HSP70 expression following exposure to magnetic fields. J. Cell. Biochem. 69, 181-188. doi: 10.1002/(SICI)1097-4644(19980501) 69:2<181::AID-JCB8>3.0.CO;2-O

Lin, H., Opler, M., Head, M., Blank, M., and Goodman, R. (1997). Electromagnetic field exposure induces rapid, transitory heat shock factor activation in human cells. J. Cell. Biochem. 66, 482-488. doi: 10.1002/(SICI)1097-4644(19970915)66: 4<482::AID-JCB7>3.0.CO;2-H

Lorenc-Kukuła, K., Korobczak, A., Aksamit-Stachurska, A., Kostyń, K., Łukaszewicz, M., and Szopa, J. (2004). Glucosyltransferase: the gene arrangement and enzyme function. Cell. Mol. Biol. Lett. 9, 935-946.

Łukaszewicz, M., Jerouville, B., and Boutry, M. (1998). Signs of translational regulation within the transcript leader of a plant plasma membrane $\mathrm{H}+$-ATPase gene. Plant J. 14, 413-423. doi: 10.1046/j.1365-313X.1998.00139.x

Łukaszewicz, M., Matysiak-Kata, I., Skala, J., Fecka, I., Cisowski, W., and Szopa, J. (2004). Antioxidant capacity manipulation in transgenic potato tuber by changes in phenolic compounds content. J. Agric. Food Chem. 52, 1526-1533. doi: $10.1021 / \mathrm{jf034482 \textrm {k }}$

Łukaszewicz, M., and Szopa, J. (2005). Pleiotropic effect of flavonoid biosynthesis manipulation in transgenic potato plants. Acta Physiol. Plant. 27, 221-228. doi: $10.1007 /$ s11738-005-0026-2

Maffei, M. E. (2014). Magnetic field effects on plant growth, development, and evolution. Front. Plant Sci. 5:00445. doi: 10.3389/fpls.2014.00445

Manzella, N., Bracci, M., Ciarapica, V., Staffolani, S., Strafella, E., Rapisarda, V., et al. (2015). Circadian gene expression and extremely low-frequency magnetic fields: an in vitro study. Bioelectromagnetics 36, 294-301. doi: 10.1002/bem. 21915

Meggers, E., Michel-Beyerle, M. E., and Giese, B. (1998). Sequence dependent long range hole transport in DNA. J. Am. Chem. Soc. 120, 12950-12955. doi: 10.1021/ja983092p

Meister, R. J., Williams, L. A., Monfared, M. M., Gallagher, T. L., Kraft, E. A., Nelson, C. G., et al. (2004). Definition and interactions of a positive regulatory element of the Arabidopsis INNER NO OUTER promoter. Plant J. 37, 426-438. doi: 10.1046/j.1365-313X.2003.01971.x

Michelet, B., Łukaszewicz, M., Dupriez, V., and Boutry, M. (1994). A plant plasma membrane proton-ATPase gene is regulated by development and environment and shows signs of a translational regulation. Plant Cell 6, 1375-1389. doi: $10.2307 / 3869975$

Murashige, T., and Skoog, F. (1962). A revised medium for rapid growth and bioassays with tobacco tissue culture. Physiol. Plant. 51, 493-497.

Porath, D., Bezryadin, A., de Vries, S., and Dekker, C. (2000). Direct measurement of electrical transport through DNA molecules. Nature 403, 635-638. doi: 10. $1038 / 35001029$

R Development Core Team (2014). R: A Language and Environment for Statistical Computing. Vienna: R Foundation for Statistical Computing. Available at: https://www.R-project.org/

Roig, C., Pozzi, C., Santi, L., Müller, J., Wang, Y., Stile, M. R., et al. (2004). Genetics of barley hooded suppression. Genetics 167, 439-448. doi: 10.1534/genetics.167. 1.439

Sangwan, I., and O'Brian, M. R. (2002). Identification of a soybean protein that interacts with GAGA element dinucleotide repeat DNA. Plant Physiol. 129, 1788-1794. doi: 10.1104/pp.002618

Santi, L., Wang, Y., Stile, M. R., Berendzen, K., Wanke, D., Roig, C., et al. (2003). The GA octodinucleotide repeat binding factor BBR participates in the 
transcriptional regulation of the homeobox gene Bkn3. Plant J. 34, 813-826. doi: 10.1046/j.1365-313X.2003.01767.x

Szopa, J., Czuj, T., and Łukaszewicz, M. (2003a). The analysis of 14-3-3 gene family. Biotechnologia 3, 95-106.

Szopa, J., Łukaszewicz, M., Aksamit, A., Korobczak, A., and Kwiatkowska, D. (2003b). Structural organisation, expression, and promoter analysis of a 16R isoform of 14-3-3 protein gene from potato. Plant Physiol. Biochem. 41, 417423. doi: 10.1016/S0981-9428(03)00048-2

Sztafrowski, D., Wróblewski, Z., Łukaszewicz, M., Sikorski, A., and Majkowski, M. (2011). "Magnetic field $50 \mathrm{~Hz}$ : its influence on living cells HL-60," in Proceedings of the 2011 10th International Conference on Environment and Electrical Engineering, eds M. Caciotta and Z. Leonowicz (Rome: IEEE), 1-4.

Vaquero, A., Blanch, M., Espinás, M. L., and Bernués, J. (2008). Activation properties of GAGA transcription factor. Biochim. Biophys. Acta 1779, 312-317. doi: 10.1016/j.bbagrm.2008.02.005

Vulevic, B., and Osmokrovic, P. (2011). Survey of ELF magnetic field levels in households near overhead power lines in Serbia. Radiat. Prot. Dosimetry 145, 385-388. doi: 10.1093/rpd/ncq439

Wan, C., Fiebig, T., Kelley, S. O., Treadway, C. R., Barton, J. K., and Zewail, A. H. (1999). Femtosecond dynamics of DNA-mediated electron transfer. Proc. Natl. Acad. Sci. U.S.A. 96, 6014-6019. doi: 10.1073/pnas.96.11.6014

Wanke, D., Hohenstatt, M. L., Dynowski, M., Bloss, U., Hecker, A., Elgass, K., et al. (2011). Alanine zipper-like coiled-coil domains are necessary for homotypic dimerization of plant GAGA-factors in the nucleus and nucleolus. PLoS ONE 6:e16070. doi: 10.1371/journal.pone.0016070
Wilkins, R. C., and Lis, J. T. (1997). Dynamics of potentiation and activation: GAGA factor and its role in heat shock gene regulation. Nucleic Acids Res. 25, 3963-3968. doi: 10.1093/nar/25.20.3963

Xu, X., Pan, S., Cheng, S., Zhang, B., Mu, D., Ni, P., et al. (2011). Genome sequence and analysis of the tuber crop potato. Nature 475, 189-195. doi: 10.1038 /nature10158

Zaporozhan, V., and Ponomarenko, A. (2010). Mechanisms of geomagnetic field influence on gene expression using influenza as a model system: basics of physical epidemiology. Int. J. Environ. Res. Public Health 7, 938-965. doi: 10. 3390/ijerph7030938

Zmyslony, M., Kubacki, R., Aniolczyk, H., Kieliszek, J., Trzaska, H., Bienkowski, P. et al. (2005). [Verification of polish regulations of maximum permissible intensities in electromagnetic fields by the commission for bioelectromagnetic issues of the polish radiation research society]. Med. Pr. 56, 501-513.

Conflict of Interest Statement: The authors declare that the research was conducted in the absence of any commercial or financial relationships that could be construed as a potential conflict of interest.

Copyright (C) 2017 Sztafrowski, Aksamit-Stachurska, Kostyn, Mackiewicz and Łukaszewicz. This is an open-access article distributed under the terms of the Creative Commons Attribution License (CC BY). The use, distribution or reproduction in other forums is permitted, provided the original author(s) or licensor are credited and that the original publication in this journal is cited, in accordance with accepted academic practice. No use, distribution or reproduction is permitted which does not comply with these terms. 